Author affiliations appear at the end of this article.

Published online ahead of print at www.jco.org on July 25, 2016

Supported by Karyopharm Therapeutics.

Presented in part at the 50th Annua Meeting of the American Society of Clinical Oncology (ASCO), Chicago, IL, May 30-June 3, 2014, and the 51st ASCO Annual Meeting, Chicago, IL, May 29-June 2, 2015.

Authors' disclosures of potential conflicts of interest are found in the article online at www.jco.org. Author contributions are found at the end of this article.

Clinical trial information: NCT01896505.

Corresponding author: Mrinal M.

Gounder, MD, Department of Medicine, Memorial Sloan Kettering Cancer Center Weill Cornell Medical College, 300 E 66th St \#1075, New York, NY 10065;

e-mail: gounderm@mskcc.org

(C) 2016 by American Society of Clinical Oncology

$0732-183 X / 16 / 3426 w-3166 w / \$ 20.00$

DOI: $10.1200 / J C O .2016 .67 .6346$

\title{
Phase IB Study of Selinexor, a First-in-Class Inhibitor of Nuclear Export, in Patients With Advanced Refractory Bone or Soft Tissue Sarcoma
}

Mrinal M. Gounder, Alona Zer, William D. Tap, Samer Salah, Mark A. Dickson, Abha A. Gupta, Mary Louise Keohan, Herbert H. Loong, Sandra P. D’Angelo, Stephanie Baker, Mercedes Condy, Kjirsten Nyquist-Schultz, Lanier Tanner, Joseph P. Erinjeri, Francis H. Jasmine, Sharon Friedlander, Robert Carlson, Thaddeus J. Unger, Jean-Richard Saint-Martin, Tami Rashal, Joel Ellis, Michael Kauffman, Sharon Shacham, Gary K. Schwartz, and Albiruni Ryan Abdul Razak

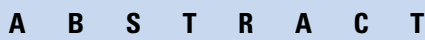

\section{Purpose}

We evaluated the pharmacokinetics (PKs), pharmacodynamics, safety, and efficacy of selinexor, an oral selective inhibitor of nuclear export compound, in patients with advanced soft tissue or bone sarcoma with progressive disease.

\section{Patients and Methods}

Fifty-four patients were treated with oral selinexor twice per week (on days 1 and 3) at one of three doses $\left(30 \mathrm{mg} / \mathrm{m}^{2}, 50 \mathrm{mg} / \mathrm{m}^{2}\right.$, or flat dose of $60 \mathrm{mg}$ ) either continuously or on a schedule of 3 weeks on, 1 week off. PK analysis was performed under fasting and fed states (low $v$ high fat content) and using various formulations of selinexor (tablet, capsule, or suspension). Tumor biopsies before and during treatment were evaluated for pharmacodynamic changes.

\section{Results}

The most commonly reported drug-related adverse events (grade 1 or 2) were nausea, vomiting, anorexia, and fatigue, which were well managed with supportive care. Commonly reported grade 3 or 4 toxicities were fatigue, thrombocytopenia, anemia, lymphopenia, and leukopenia. Selinexor was significantly better tolerated when administered as a flat dose on an intermittent schedule. PK analysis of selinexor revealed a clinically insignificant increase (approximately 15\% to 20\%) in drug exposure when taken with food. Immunohistochemical analysis of paired tumor biopsies revealed increased nuclear accumulation of tumor suppressor proteins, decreased cell proliferation, increased apoptosis, and stromal deposition. Of the 52 patients evaluable for response, none experienced an objective response by RECIST (version 1.1); however, 17 (33\%) showed durable ( $\geq 4$ months) stable disease, including seven (47\%) of 15 evaluable patients with dedifferentiated liposarcoma.

\section{Conclusion}

Selinexor was well tolerated at a 60-mg flat dose on a 3-weeks-on, 1-week-off schedule. There was no clinically meaningful impact of food on PKs. Preliminary evidence of anticancer activity in sarcoma was demonstrated

\section{J Clin Oncol 34:3166-3174. (C) 2016 by American Society of Clinical Oncology}

\section{INTRODUCTION}

Soft tissue and bone sarcomas are rare tumors of mesenchymal origin with a wide range of natural histories, epidemiologies, genetic aberrations, treatment responses, and prognoses. ${ }^{1}$ For patients with metastatic disease, treatment options are limited, and the median overall survival is 10 to 18 months, highlighting the need for new therapies. ${ }^{2}$
Aberrations in tumor suppressor proteins (TSPs) have been well described in many sarcoma subtypes and are thought to contribute to tumorigenesis and drug resistance. ${ }^{3,4}$ A majority of TSPs exert their activity in the nucleus and subsequently undergo cytoplasmic degradation. ${ }^{5}$ Exportin 1 (XPO1), also called chromosome region maintenance protein 1 (CRM1), is a critical mediator of nuclear export responsible for shuttling more than 200 known cargo proteins from the nucleus to the 
cytoplasm, including TSPs and anti-inflammatory and growthregulating proteins. ${ }^{6,7}$ XPO1 overexpression has been reported in several hematologic and solid malignancies and is correlated with poor patient outcomes. ${ }^{7-12}$ XPO1 overexpression is one mechanism by which neoplastic cells inactivate TSPs through nuclear exclusion and thereby circumvent cell-cycle regulation, genome survey, and apoptosis. ${ }^{9}$

Selinexor is a novel, orally bioavailable small molecule, which inhibits XPO1 by covalently and reversibly binding cysteine-528, an essential residue for XPO1 cargo binding. ${ }^{6}$ Inhibition of XPO1 results in nuclear accumulation of p53, pRb, p21, p27, BRCA1/2, FOXOs, survivin, and other proteins. ${ }^{6,7}$ Accumulation of TSPs in the nucleus restores cell-cycle checkpoints and induces growth arrest and apoptosis in malignant cells. ${ }^{13,14}$ Preclinical studies in a wide range of sarcoma cell lines and xenografts have demonstrated robust antitumor activity. ${ }^{15,16}$ In a parallel phase I study of selinexor in solid tumors (ClinicalTrials.gov identifier 01607905 ), the maximum administered dose was $85 \mathrm{mg} / \mathrm{m}^{2}$ (on days 1 and 3 ); however, based on chronic tolerability, the recommended phase II dose was established as $35 \mathrm{mg} / \mathrm{m}^{2} .{ }^{17}$ On the basis of the novel mechanism of action and robust preclinical data, we conducted a parallel phase IB study of selinexor in patients with sarcoma to evaluate the effects of food and formulation on pharmacokinetics (PKs), pharmacodynamics (PDs), and efficacy.

\section{PATIENTS AND METHODS}

\section{Patient Selection}

Patients age 18 years or older were eligible after histologic confirmation of sarcoma measurable by RECIST (version 1.1), evidence of radiographic progression at study entry, at least one prior anticancer regimen when appropriate for the specific histology, Eastern Cooperative Oncology Group performance status of 0 to 1 , body surface area between $1.4 \mathrm{~m}^{2}$ or greater and $2.5 \mathrm{~m}^{2}$ or less (only for cohort four, five, and six), and adequate organ function defined as adequate hepatic function (bilirubin $<$ $1.5 \times$ the upper limit of normal; AST and ALT $<3 \times$ the upper limit of normal), hematopoietic reserve (absolute neutrophil count $\geq 1,000 / \mathrm{mm}^{3}$; platelet count $\left.\geq 100 \times 10^{9} / \mathrm{L}\right)$, and creatinine clearance $(\geq 30 \mathrm{ml} / \mathrm{min}){ }^{18}$ Patients with coexisting uncontrolled medical conditions, HIV/AIDS, CNS metastases, or GI dysfunctions that interfered with drug absorption were excluded. The study was initiated after approval from the institutional review board and was conducted in accordance with the Declaration of Helsinki. Written informed consent was obtained from patients. The study was conducted in the United States (Memorial Sloan Kettering Cancer Center) and Canada (Princess Margaret Hospital). Data cutoff was December 7, 2015.

\section{Treatment}

Three cohorts with varying doses, schedules, and formulations were evaluated (Appendix Fig A1, online only). Patients in the food-effect arm (cohort one) received selinexor orally at a starting dose of $30 \mathrm{mg} / \mathrm{m}^{2}$ twice week (on days 1 and 3 ) over a 28-day cycle. This dose and schedule were selected from a parallel phase I study. ${ }^{17}$ Each patient in this cohort was evaluated under four different conditions: fasting, low-fat diet and high-fat diet with tablet formulation, and low-fat diet with capsule formulation. Fasting condition (treatment A) was a minimum of 10 hours overnight fast followed by selinexor administration and an additional 4 hours without food. For fed state, patients fasted overnight for 10 hours and then received a high- (treatment B, 800 to $1,000 \mathrm{Kcal} / \mathrm{meal}$ ) or low-fat meal (treatment C,
500 to $600 \mathrm{Kcal} / \mathrm{meal}$ ), provided by the study sponsor, followed by selinexor within 30 minutes of the meal. ${ }^{19}$ In addition, a capsule formulation was evaluated with a low-fat meal (treatment D, 500 to $600 \mathrm{Kcal} / \mathrm{meal}$ ). Patients were randomly assigned to one of two treatment sequences, which were either treatment A followed by B, C, and D or treatment B followed by A, D, and C. Patients were required to complete all four arms of the study and to consume at least $75 \%$ of the meal to be evaluable for PK analysis. Cohort two consisted of patients treated with selinexor $50 \mathrm{mg} / \mathrm{m}^{2}$ twice per week (on days 1 and 3), receiving oral tablets within 30 minutes of food consumption. This higher dose was chosen to evaluate efficacy, toxicity, and PDs in sarcoma and was selected based on the parallel phase I study of selinexor in solid tumors. ${ }^{17}$ Analysis of toxicities in cohorts one and two, along with the parallel phase I study, suggested that flat dosing and an interrupted schedule would be better tolerated. Cohort three was designed to evaluate selinexor at a 60-mg flat dose (approximately $35 \mathrm{mg} / \mathrm{m}^{2}$ ) twice per week (on days 1 and 3) on a 3-weeks-on, 1-weekoff schedule. In cohort three, the PKs of three different formulations (first-generation tablet, second-generation tablet, or suspension) were evaluated.

\section{Follow-Up Assessments}

At baseline and during the study, patients underwent review of medical history; review of concurrent medications; physical, neurologic, and ophthalmic examinations; electrocardiogram; and complete blood and comprehensive metabolic panels. Radiographic imaging by computed tomography or magnetic resonance imaging was performed at baseline and repeated every 8 weeks. All patients who received at least one dose of selinexor were evaluated for safety according to National Cancer Institute Common Terminology Criteria for Adverse Events (version 4.03).

\section{PKs}

In the food-effect and formulation cohorts, peripheral blood $(2 \mathrm{~mL})$ was collected on day 1 before dosing and 15 minutes, 30 minutes, and $1,1.5,2,3,4,5,6,8,10$, and 24 hours after dosing. PKs were calculated by standard noncompartmental analysis using PK Solutions software (Summit Research Services, Montrose, CO). Area under the concentration-time curve (AUC) was calculated by the linear trapezoidal method.

\section{PDs}

When safe and feasible, paired tumor biopsies were obtained at baseline and after approximately 3 to 4 weeks of treatment. Immunohistochemical staining was performed by study sponsor on formalin-fixed, paraffin-embedded specimens using a BioGenex I6000 automated immunostainer (BioGenex, Fremont, CA) as described by manufacturer. Evaluations included tumor cell morphology (hematoxylin and eosin [HE]; Richard-Allan Scientific, San Diego, CA; Masson's trichrome; Poly Scientific, Bay Shore, NY), apoptosis (ApopTag S71003; EMD Millipore, Billerica, MA), proliferation (Ki67: 275R-18; Cell Marque, Rocklin, CA), and XPO1 and TSP expression and localization (XPO1: product sc-5595; Santa Cruz Biotech, Dallas, TX; FOXO1: product 2880; Cell Signaling Technology, Danvers, MA; p21: product 2947, Cell Signaling Technology; p53: product sc126; Santa Cruz Biotech). Representative images were captured using the Aperio ScanScope AT Turbo at $20 \times$ magnification (Leica Biosystems, Buffalo Grove, IL). Nuclear Ki67 and Masson's trichrome staining were quantified using Definiens Tissue Studio software (Definiens, Munich, Germany). An independent, blinded pathologist reviewed and scored the paired biopsies for liposarcoma (LPS) samples.

\section{Statistics}

Sample size was calculated based on US Food and Drug Administration guidelines for food-effect studies. ${ }^{19}$ We used descriptive statistics for continuous variables and frequency counts for categorical variables. 
Paired Student $t$ test was used to compare individual plasma PK parameters, including maximum plasma concentration, $\mathrm{AUC}_{0-\infty}$, and time to peak plasma concentration. $Z$ test for proportions was used to compare frequently reported adverse events (AEs) among cohorts. Data were considered statistically significant when $P$ was less than .05 .

\section{RESULTS}

\section{Patient Characteristics and Treatment}

Fifty-four patients were enrolled, with 19 in cohort one $\left(30 \mathrm{mg} / \mathrm{m}^{2}\right.$; food effect), 17 in dose-expansion cohort two $\left(50 \mathrm{mg} / \mathrm{m}^{2}\right)$, and 18 in cohort three $(60-\mathrm{mg}$ flat and intermittent dose; formulation). Baseline characteristics of the patients are summarized in Table 1. Patients had a median age of 55 years (range, 18 to 86 years); $57 \%$ were women. Patients had an Eastern Cooperative Oncology Group performance status of 0 or $1(100 \%)$, a median of two (range, zero to nine) prior systemic therapies, and a range of tumor types, with the most common being LPS ( $\mathrm{n}=19$ [33\%]) followed by leiomyosarcoma LMS; $n=12$ [22\%]).

\begin{tabular}{|c|c|}
\hline Characteristic & No. (\%) \\
\hline \multicolumn{2}{|l|}{ Age, years } \\
\hline Median & 55 \\
\hline Range & $18-86$ \\
\hline \multicolumn{2}{|l|}{ Sex } \\
\hline Female & $31(57)$ \\
\hline Male & $23(43)$ \\
\hline \multicolumn{2}{|l|}{ Race } \\
\hline Asian & $8(15)$ \\
\hline Black or African American & $3(6)$ \\
\hline White & $41(76)$ \\
\hline Not reported & $2(4)$ \\
\hline \multicolumn{2}{|l|}{ No. of prior regimens } \\
\hline Median & 2 \\
\hline Range & $0-9$ \\
\hline $1-2$ & $23(43)$ \\
\hline $3-4$ & $17(31)$ \\
\hline $5-6$ & $5(9)$ \\
\hline$\geq 7$ & $5(9)$ \\
\hline 0 & $4(7)$ \\
\hline \multicolumn{2}{|l|}{ ECOG performance status } \\
\hline 0 & $28(52)$ \\
\hline 1 & $26(48)$ \\
\hline \multicolumn{2}{|l|}{ Sarcoma subtype } \\
\hline WD/DD liposarcoma & $16(30)$ \\
\hline Myxoid liposarcoma & $3(6)$ \\
\hline Leiomyosarcoma & $12(22)$ \\
\hline Synovial sarcoma & $4(7)$ \\
\hline Other* & $19(35)$ \\
\hline \multicolumn{2}{|c|}{$\begin{array}{l}\text { Abbreviations: DD, dedifferentiated; ECOG, Eastern Cooperative Oncology } \\
\text { Group; WD, well differentiated. } \\
\text { *OOther includes: aveolar soft part sarcoma }(n=1) \text {, chondroblastic osteosarcoma } \\
(n=1) \text {, chondrosarcoma }(n=1) \text {, chordoma }(n=1) \text {, clear cell sarcoma }(n=1) \\
\text { desmoplastic small round-cell tumor }(n=1) \text {, endometrial stromal sarcoma }(n=2) \text {, } \\
\text { Ewing sarcoma }(n=1) \text {, intimal sarcoma }(n=1) \text {, malignant peripheral-nerve sheath } \\
\text { tumor }(n=1) \text {, malignant phyllodes tumor }(n=1) \text {, extraskeletal myxoid chon } \\
\text { drosarcoma }(n=1) \text {, myxofibrosarcoma }(n=1) \text {, primitive neuroectodermal tumor } \\
\text { ( } n=1) \text {, undifferentiated pleomorphic sarcoma }(n=1) \text {, spindle cell neoplasm with } \\
\text { squamous differentiation }(n=1) \text {, spindle cell sarcomatoid carcinoma }(n=1) \text {, and } \\
\text { undifferentiated pleomorphic sarcoma }(n=1) \text {. }\end{array}$} \\
\hline
\end{tabular}

PKs

Of the 37 patients in cohorts one and three, 24 were considered evaluable for PK analysis. Figure 1 and Appendix Table A1 (online only) summarize the effects of food and formulation on drug metabolism. There were no significant differences in the PK parameters (maximum plasma concentration, time to peak plasma concentration, $\mathrm{AUC}_{0-\infty}$, clearance, and half-life) between high- and low-fat meals or the various formulations. When compared with that for the fasting state, the $\mathrm{AUC}_{0-\infty}$ was significantly higher with a high- $(P=.003)$ or low-fat meal $(P=.009)$; however, these differences were modest (approximately 15\% to 20\%) and not clinically relevant. ${ }^{19}$

\section{Safety and Tolerability}

The highest-grade drug-related AEs occurring in at least 10\% of patients with sarcoma treated with selinexor are listed in Table 2. The most frequently reported toxicities were nausea, fatigue, anorexia, dysgeusia, and vomiting, which were primarily grade 1 or 2 and well controlled with antinausea medications (ondansetron, olanzapine, or lorazepam) and appetite stimulants (olanzapine and megestrol). Grade 3 or 4 toxicities included fatigue, diarrhea thrombocytopenia, anemia, and neutropenia. Ten drug-related serious AEs were noted in nine patients, including nausea, vomiting, diarrhea, lung infection, maculopapular rash, central autonomic dysfunction, thrombocytopenia, and anemia, which led to dose interruptions, reductions, or discontinuations. All patients recovered with supportive care. The 60-mg flat dose was better tolerated with significantly lower dizziness $(P=.006)$, nausea $(P=.03)$, vomiting $(P=.04)$, and anorexia $(P=.04)$ and trends toward significance for fatigue $(P=.1)$, neutropenia $(P=.08)$, and blurry vision $(P=.06)$.

\section{Antitumor Efficacy}

A total of 52 patients with progressive disease were evaluable for response by RECIST (version 1.1). There were no complete or partial responses. Thirty (58\%) of 52 patients showed stable disease (SD), with 17 (33\%) experiencing SD for 4 months or longer. Thirteen $(30 \%)$ of 43 evaluable patients showed a reduction in target lesion size from baseline (Fig 2A). Antitumor activity was particularly noted in patients with dedifferentiated LPS (DDLPS), with six (40\%) of 15 patients showing a reduction in target lesion size from baseline, and seven (47\%) of 15 patients showing SD for 4 months or longer (Fig $2 \mathrm{~B}$ ). Because only patients with progressive disease were enrolled in the study, the time to progression (TTP) ratio (ie, ratio of TTP with selinexor to TTP with prior therapy) or growth modulation index (GMI) was calculated for each patient, using a previously described threshold of 1.3 or greater as a sign of potential drug activity and improved overall survival (Appendix Fig A2, online only). ${ }^{20-23}$ Sixteen (39\%) of 41 evaluable and seven (54\%) of 13 patients with DDLPS had GMI of 1.3 or greater. Figure 3 shows representative images of antitumor activity in patients with DDLPS.

\section{PD Analysis}

Sixteen patients underwent successful paired tumor biopsies. Target inhibition was confirmed by increased nuclear 


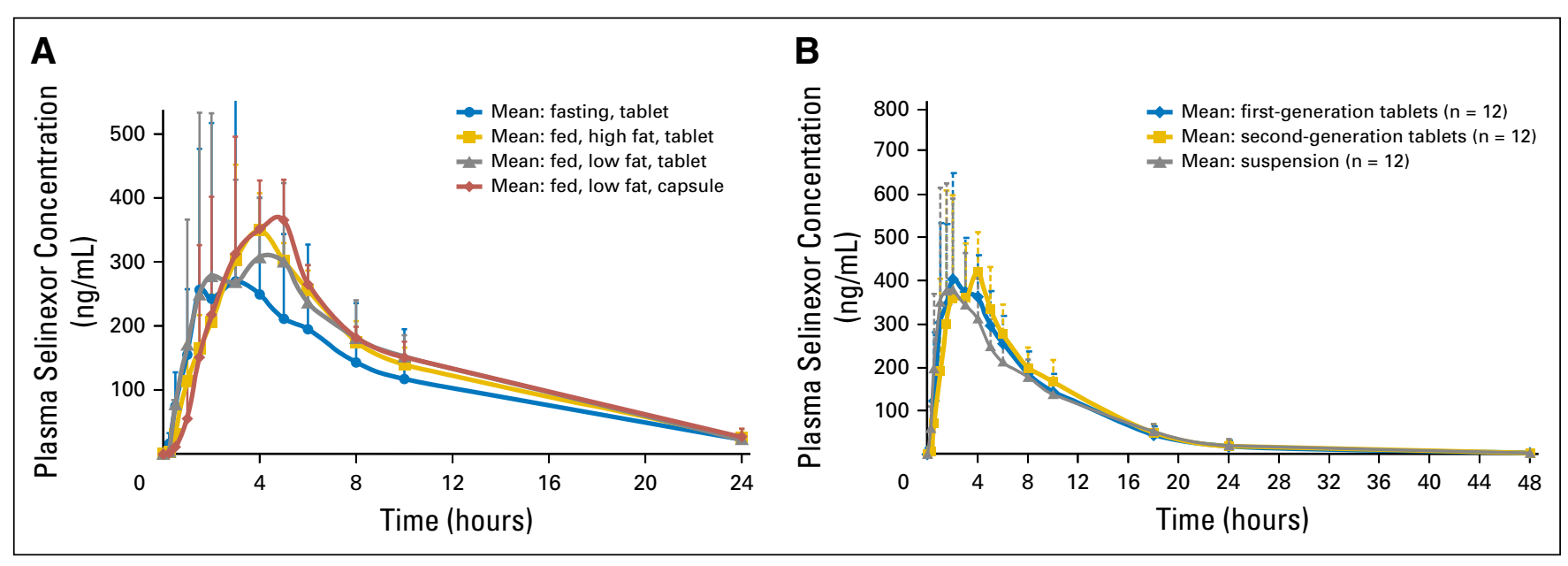

Fig 1. (A) Effect of food on the exposure (area under the curve [AUC]) of selinexor as a function of time ( 0 to 24 hours). Plasma concentration of selinexor (first-generation

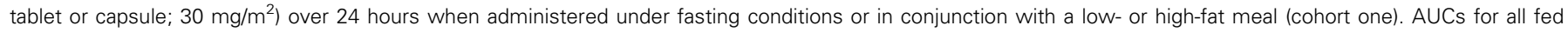

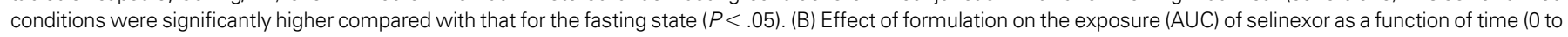
48 hours). Comparison of selinexor (60 mg) pharmacokinetics for first- and second-generation tablets and oral suspension over 48 hours (cohort three).

accumulation of XPO1 and cargo proteins (p53, p21, and FOXO1). Furthermore, immunohistochemical staining showed corresponding decrease in cellularity (HE), proliferation (Ki67), and increase in apoptosis (ApopTag) and fibrosis (Masson's trichrome) after selinexor treatment (Fig 4; Appendix Table A2, online only; Appendix Fig A3, online only), confirming the results of preclinical studies. ${ }^{15,16}$

\section{DISCUSSION}

A vast majority of cancer genomes harbor driver alterations in TSPs, which play critical roles in cancer initiation, progression, and metastasis. $^{24,25}$ Targeting TSPs, namely reactivating or repairing proteins, is significantly more challenging, as evidenced by the disproportionate number of kinase inhibitors that are approved or in development. ${ }^{26}$ Novel approaches to reactivating TSPs include targeting the negative regulators (eg, TP53 and MDM2 inhibitors), inhibiting unopposed oncogenic pathways (eg, PTEN deletion and PI3KCA inhibitors), initiating synthetic lethality (eg, BRCA1/2 and poly (ADP-ribose) polymerase inhibitors), and others. ${ }^{26}$ Inhibition of nucleocytoplasmic shuttling as an anticancer strategy is an emerging field that targets aberrant nuclear import/export machinery. ${ }^{17,27}$ XPO1 binds nuclear proteins that bear a leucinerich nuclear export signal (NES) in a guanosine triphosphatedependent manner, which are then transported across the nuclear pore complex for cytoplasmic activity or degradation. More than 200 different proteins harbor NES motifs and are cargo proteins for XPO1, including p53, MDM2, CDKN1A/p21, CDKN1B/p27, FOXO3, AKT1, BRCA1/2, WEE1, SMAD4, APC, and NFKB1A. ${ }^{28}$ Treatment with selinexor, a first-in-class selective inhibitor of nuclear export compound, results in nuclear retention of TSPs and activation of apoptosis, cell-cycle arrest, and/or senescence.

In this phase IB clinical trial of selinexor, we evaluated the therapeutic potential of reactivating TSPs in advanced sarcoma by inhibiting XPO1. We determined the safety and toxicity of a new schedule, effects of food and formulation on drug metabolism, PD effects, and efficacy in sarcoma, particularly in DDLPS. The recommended phase II dose in patients with advanced sarcoma is $60 \mathrm{mg}$ (approximately $35 \mathrm{mg} / \mathrm{m}^{2}$ ) orallly twice per week (3-weekson, 1-week-off schedule). Although food did not affect PKs, we recommend selinexor be taken with a light meal to potentially alleviate GI-related adverse effects. In the entire cohort, 14 (26\%) of 54 patients required dose interruption or reduction because of AEs. As expected, patients treated at a lower dose and intermittent schedule reported improvement in nausea, vomiting, anorexia, dizziness, fatigue, and blurry vision. We observed that earlier institution of supportive care, such as ondansetron, olanzapine, low-dose dexamethasone, or megesterol, helped alleviate severity of symptoms. Reversible thrombocytopenia of any grade was noted in approximately half of the study population, including grade 3 or 4 events in $9 \%$ of patients. Selinexor-induced thrombocytopenia results from the inhibition of hematopoietic stem-cell maturation to megakaryocytes, without affecting hematopoietic stem-cell survival, platelet activation, mature megakaryocyte survival, or proplatelet formation. ${ }^{29}$ In this study, thrombocytopenia was reversible with platelet-stimulating growth factors, and evaluation of two patients with selinexor-induced thrombocytopenia showed normal marrow with maturing trilineage hematopoiesis. Some patients reported dizziness despite adequate volume repletion. Although extensive neurologic evaluation was unrevealing, we suspect this was likely drug related, because symptoms improved with dose interruption. Asymptomatic hyponatremia despite volume repletion was noted with no clear etiology. Approximately $10 \%$ of patients reported blurry vision; however, ophthalmologic evaluations were unrevealing, and symptoms resolved with drug interruption. One patient had worsening of pre-existing cataracts, and the etiology was uncertain. These findings may be the consequences of disrupting a wide range of proteins that depend on $\mathrm{XPO} 1$ for their function.

In the tumor biopsies performed to assess $\mathrm{PD}$ end points, target inhibition of XPO1 was indirectly confirmed by increased nuclear retention of TSPs ( $\mathrm{p} 53$, FOXO1, and $\mathrm{p} 21$ ) and apoptosis (ApopTag) and decreased cellularity (HE) and mitosis (Ki67). 


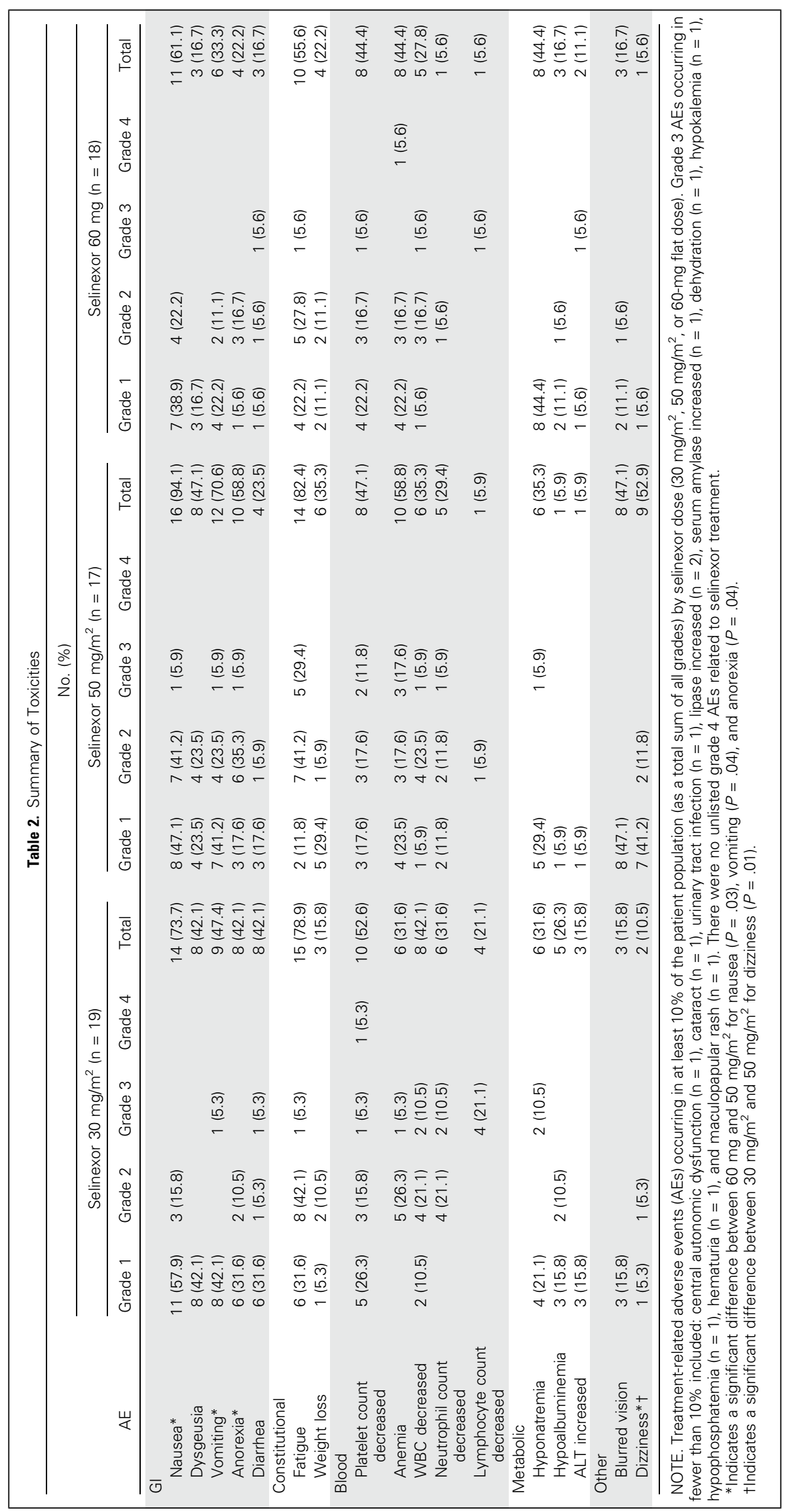




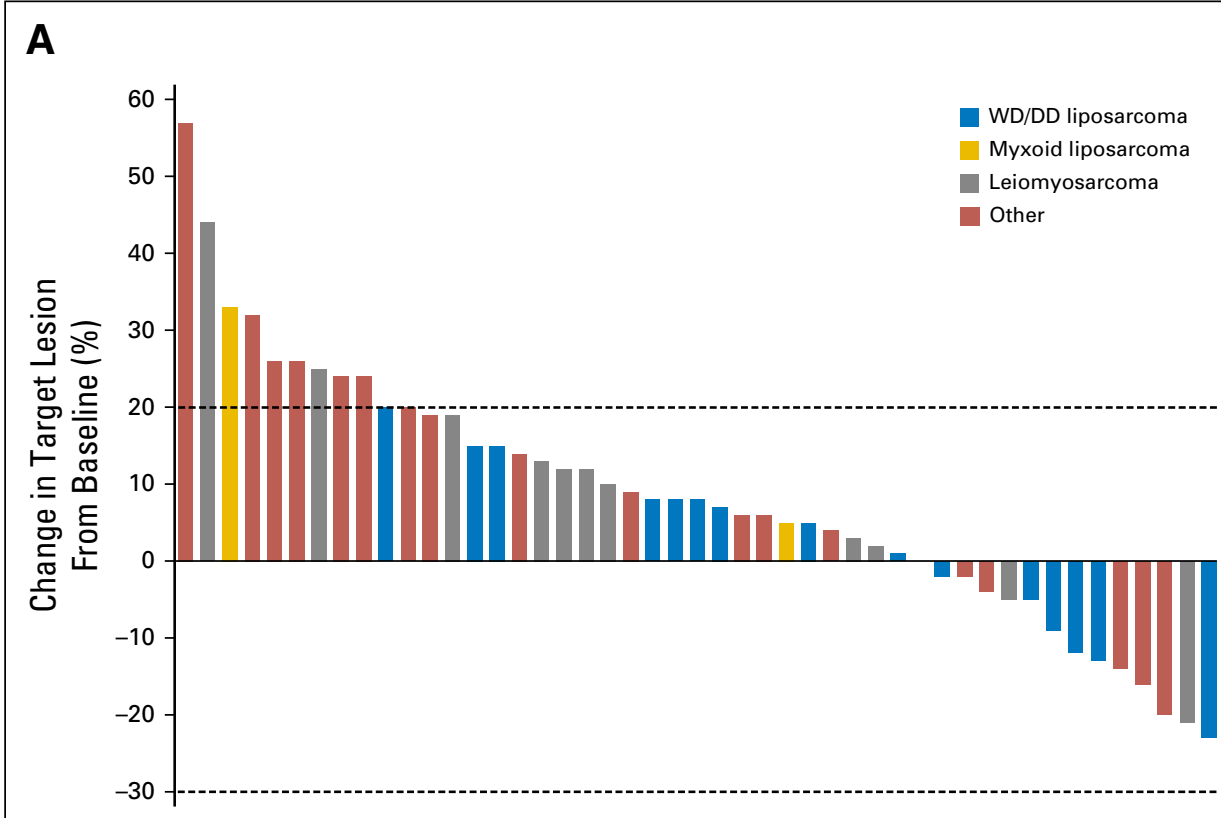

B

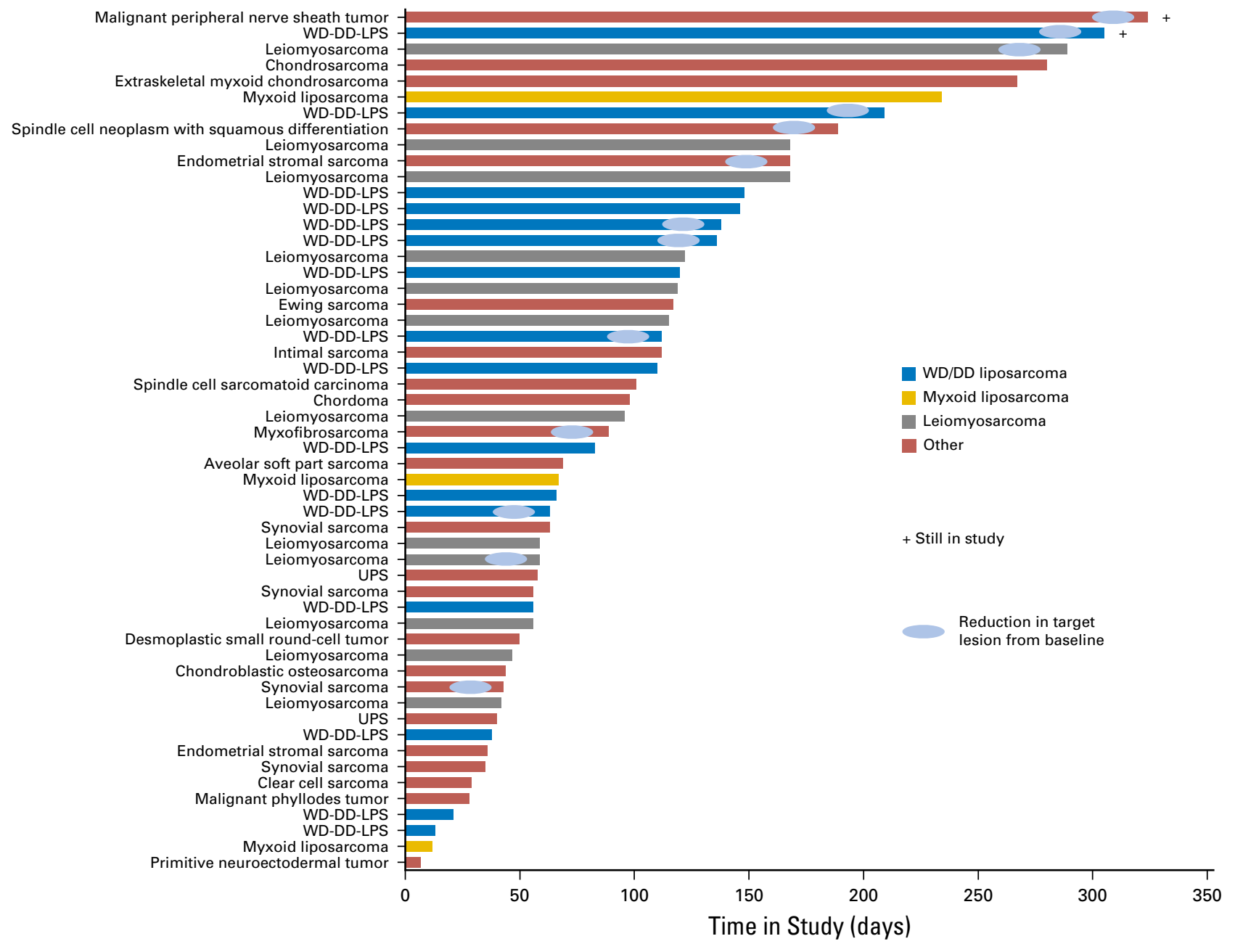



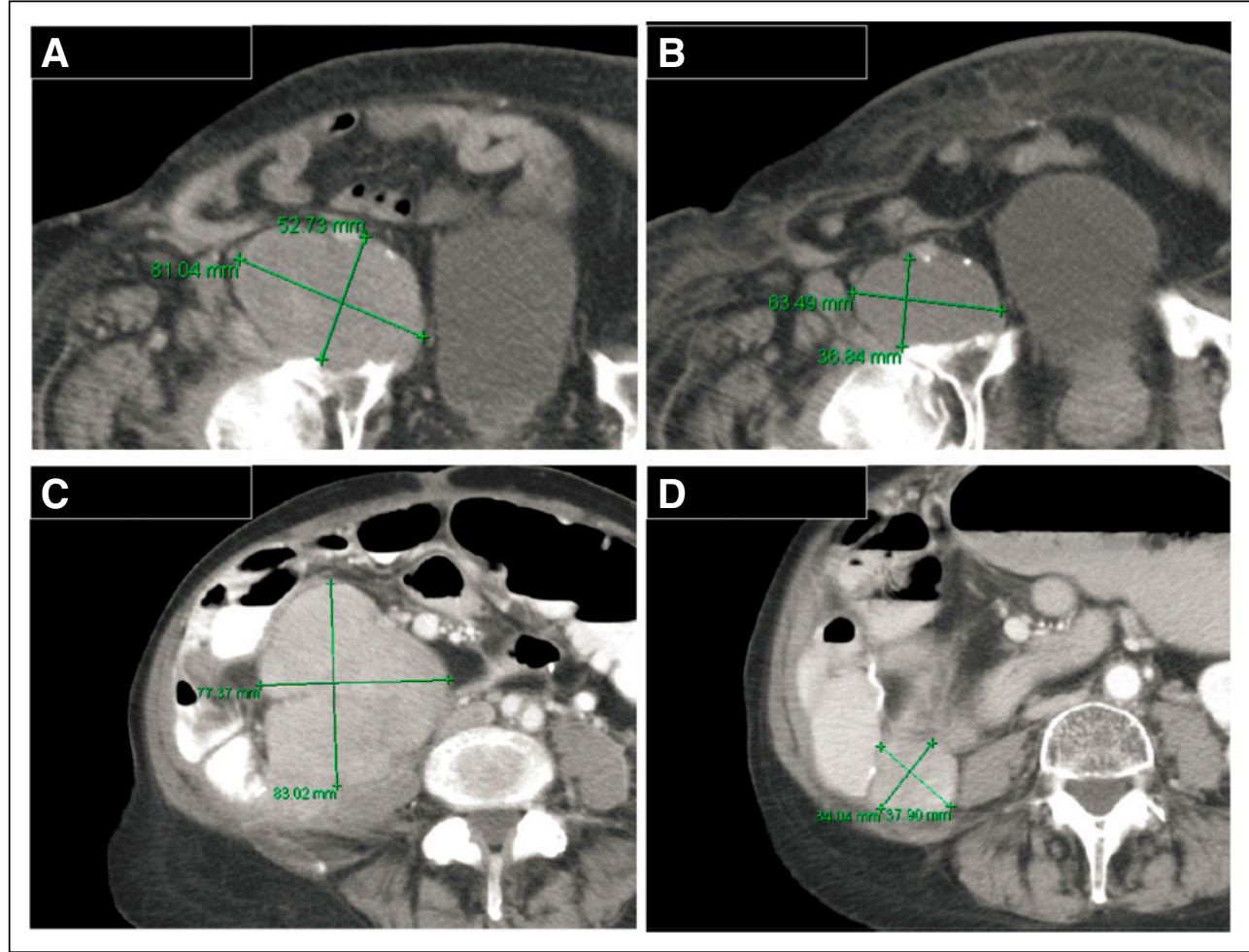

Fig 3. Radiographic images of antitumor activity in liposarcoma. (A) Baseline computed tomography (CT) scan of a target lesion in an 88-year-old man with advanced refractory dedifferentiated liposarcoma and (B) reduction in tumor size after two cycles of selinexor. (C) Baseline CT scan of a representative lesion in a 72-year-old woman with aggressive dedifferentiated liposarcoma and (D) reduction in tumor size after two cycles of selinexor. Green lines indicate lesion.

Interestingly, this was associated with increased stromal deposition and fibrosis, as evidenced by Masson's trichrome stain. We acknowledge that tumor heterogeneity and biopsy sampling variation limit our interpretation, particularly in LPS, where welldifferentiated and dedifferentiated components with varying cellularity are admixed with no clear demarcating borders. We were unable to confirm whether apoptosis was directly related to an XPO1-induced mechanism or a nonspecific stress response. In preclinical studies, selinexor decreased protein expression of XPO1 in vitro after 48 hours of treatment. ${ }^{16}$ In this study, biopsies were obtained after approximately 3 to 4 weeks of treatment and XPO1 expression was retained in the nucleus. These discordant findings require further investigation, including biopsies at earlier time points.

Of patients with progressive and refractory DDLPS at study start, $47 \%$ had durable ( $\geq 4$ months) SD, and 54\% had a GMI of 1.3 or greater. $^{21,22}$ Studies in sarcoma and solid tumors have demonstrated that this index is a sign of an active drug. Progression-free survival for systemic chemotherapies in DDLPS has been reported to be 4.6 and 2.2 to 2.6 months in the first- and second-line settings, respectively. ${ }^{30-32}$ The hallmark of DDLPS is amplification of CDK4 and MDM2 genes with near-universal presence of wild-type TP53. ${ }^{3,4}$ MDM2 is the most important negative regulator of $\mathrm{p} 53 .{ }^{33}$ MDM2 ubiquitination of $\mathrm{p} 53$ results in a conformational shift that exposes the NES domain for XPO1 interaction and export. ${ }^{34}$ In this context, selinexor targets the central pathway in DDLPS and increases nuclear p53 expression and its downstream target, p21. Histopathology is further detailed in Appendix Table A2 and Figure A3. The exact mechanism of selinexor-induced cell death and fibrosis in DDLPS is under further investigation. No biomarker of benefit or resistance was discernible in tumor analysis, although this was limited by the small sample size. Patients with LMS represented $22 \%$ of the study, and prolonged SD ( $\geq 4$ months) was seen in approximately $36 \%$ of patients. For example, a 67-year-old woman with advanced LMS was refractory to doxorubicin plus carboplatin, ifosfamide, and gemcitabine, as well as docetaxel ( 2 months) and was then treated with selinexor as a fourth-line agent. The patient experienced a $-21 \%$ tumor shrinkage and SD lasting 290 days. Evaluation of paired biopsy samples showed reduced cellularity (HE), mitosis (Ki67), increased apoptosis (ApopTag), and nuclear retention of p53, FOXO1, and p21 (Fig 4). LMS is characterized by complex genomic alterations, with a high frequency (approximately 70\%) of mutations or deletions in tumor suppressor genes such as TP53, PTEN, Rb, and CDH1. ${ }^{35}$ This suggests that activity of selinexor in LMS may occur through alternate mechanisms that need further investigation.

In the phase I study of selinexor in solid tumors (ClinicalTrials. gov identifier NCT01607905), a prolonged SD was observed in endometrial stromal sarcoma (ESS). ${ }^{17}$ On this basis, two patients

Fig 2. (A) Percent change in target lesion size from baseline for 47 evaluable patients. Quantitative target lesion assessment was not available for seven patients because

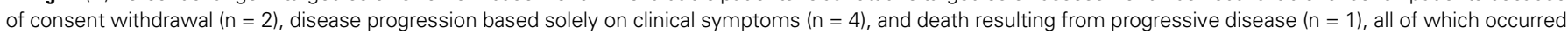

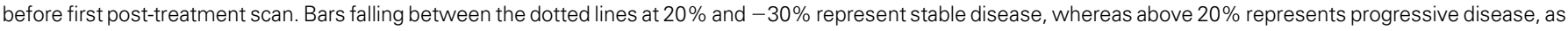

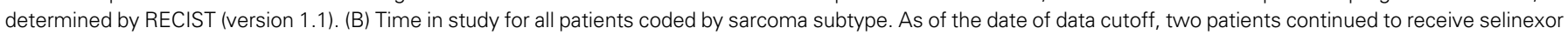
treatment. DD, dedifferentiated; LPS, liposarcoma; UPS, undifferentiated pleomorphic sarcoma; WD, well differentiated. 


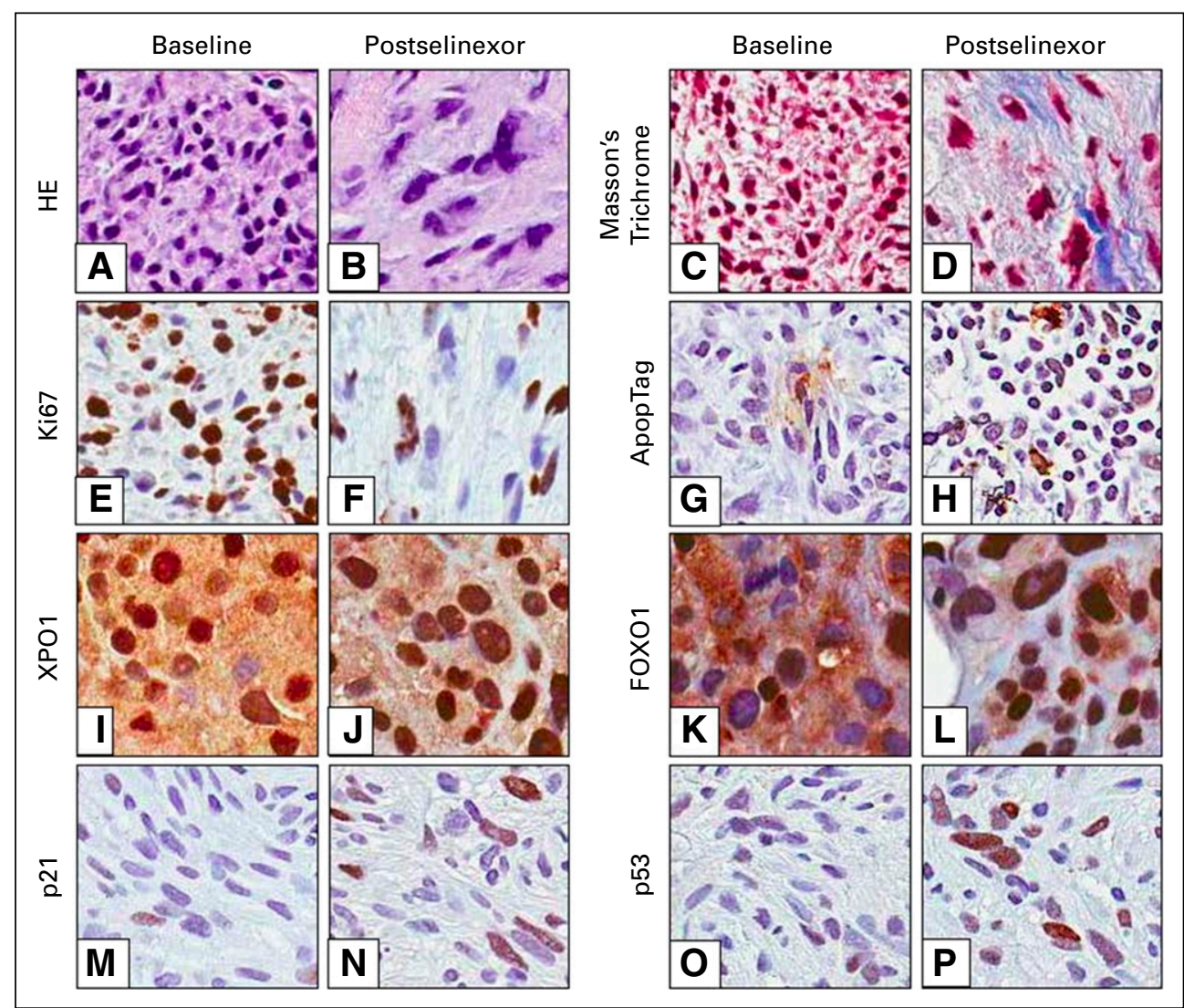

Fig 4. Patient tumor biopsies were analyzed by immunohistochemistry for morphologic and biochemical changes in response to selinexor treatment. (A, B) Hematoxylin and eosin (HE) and (C, D) Masson's trichrome staining of tumor samples taken from a patient with welldifferentiated (WD)/dedifferentiated (DD) liposarcoma at baseline and 4 weeks after receiving selinexor $50 \mathrm{mg} / \mathrm{m}^{2}$. Immunohistochemical staining (brown) of markers for (E, F) proliferation, (G, H) apoptosis, (I, J) $\mathrm{XPO1}$, and ( $\mathrm{K}$ to $\mathrm{P}) \mathrm{XPO1}$ cargo tumor suppressor proteins are also shown. Ki67 staining is from the same patient in panels $A$ to D. ApopTag, p21, and p53 images are from a patient with WD/DD liposarcoma treated with selinexor $60 \mathrm{mg}$ for 4 weeks. XPO1 and FOXO1 images are from a patient with leiomyosarcoma treated with selinexor $30 \mathrm{mg} / \mathrm{m}^{2}$ for 3 weeks. All three patients had a best response of stable disease.

with ESS were recruited to our study. One patient had experienced RECIST progression $(+35 \%$ over a 12 -week period) in another clinical trial and enrolled in this study. This patient experienced tumor reduction $(-14 \%)$ and remained in the study for 24 weeks but withdrew consent because of drug-related AEs. The second patient experienced progression after two cycles of selinexor. Further evaluation of selinexor in ESS is warranted. Preclinical studies with selinexor showed robust activity in synovial sarcoma, alveolar soft part sarcoma, and Ewing sarcoma. ${ }^{16}$ Although sample size was limited, our study failed to register a signal in these diseases.

Lastly, our study highlights the importance of conducting food-effect studies early in drug development. ${ }^{36}$ Food and formulation are regulatory requirements for oral agents, and given the shift toward oral drugs, this represents an opportunity for sponsors and investigators to evaluate signals in rare cancers where clinical trials are typically challenging to conduct. Defining proper administration is critical for success of drug development, as recently highlighted by the impact of food on toxicity of lapatinib, nilotinib, and abiraterone. ${ }^{37-42}$ We conducted a parallel phase IB study, which informed the design of several ongoing pivotal studies with selinexor. In summary, selinexor is well tolerated in patients with advanced refractory sarcoma. Prolonged disease control was noted in several tumor types, including liposarcoma and leiomyosarcoma. A randomized phase II/III clinical trial of selinexor versus placebo with crossover at progression is currently ongoing in patients with advanced DDLPS who experienced progression with prior therapies (ClinicalTrials.gov identifier NCT02606461).

\section{AUTHORS' DISCLOSURES OF POTENTIAL CONFLICTS OF INTEREST}

Disclosures provided by the authors are available with this article at www.jco.org.

\section{AUTHOR CONTRIBUTIONS}

Conception and design: Mrinal M. Gounder, Tami Rashal, Michael Kauffman, Sharon Shacham, Gary K. Schwartz

Financial support: Michael Kauffman, Sharon Shacham

Provision of study materials or patients: Mrinal M. Gounder, Albiruni Ryan Abdul Razak

Collection and assembly of data: Mrinal M. Gounder, Alona Zer,

William D. Tap, Samer Salah, Mark A. Dickson, Mary Louise Keohan,

Herbert H. Loong, Sandra P. D’Angelo, Stephanie Baker, Mercedes Condy, Kjirsten Nyquist-Schultz, Lanier Tanner, Joseph P. Erinjeri, Francis H.

Jasmine, Sharon Friedlander, Robert Carlson, Thaddeus J. Unger, Jean-Richard Saint-Martin, Tami Rashal, Joel Ellis, Michael Kauffman, Sharon Shacham, Albiruni Ryan Abdul Razak

Data analysis and interpretation: Mrinal M. Gounder, Mark A. Dickson, Abha A. Gupta, Sharon Friedlander, Robert Carlson, Thaddeus J. Unger, Jean-Richard Saint-Martin, Joel Ellis, Michael Kauffman, Sharon Shacham, Gary K. Schwartz, Albiruni Ryan Abdul Razak

Manuscript writing: All authors

Final approval of manuscript: All authors

Accountable for all aspects of the work: All authors 


\section{REFERENCES}

1. Schöffski P, Cornillie J, Wozniak A, et al: Soft tissue sarcoma: an update on systemic treatment options for patients with advanced disease. Oncol Res Treat 37:355-362, 2014

2. von Mehren $M$, Randall RL, Benjamin RS, et al: Soft tissue sarcoma, version 2.2014. J Natl Compr Canc Netw 12:473-483, 2014

3. Barretina J, Taylor BS, Banerji $S$, et al: Subtype-specific genomic alterations define new targets for soft-tissue sarcoma therapy. Nat Genet 42:715-721, 2010

4. Taylor BS, Barretina J, Maki RG, et al: Advances in sarcoma genomics and new therapeutic targets. Nat Rev Cancer 11:541-557, 2011

5. Zaidi SK, Young DW, Javed A, et al: Nuclear microenvironments in biological control and cancer. Nat Rev Cancer 7:454-463, 2007

6. Fung HY, Chook YM: Atomic basis of CRM1cargo recognition, release and inhibition. Semin Cancer Biol 27:52-61, 2014

7. Tan DS, Bedard PL, Kuruvilla J, et al: Promising SINEs for embargoing nuclear-cytoplasmic export as an anticancer strategy. Cancer Discov 4:527-537, 2014

8. Huang WY, Yue L, Qiu WS, et al: Prognostic value of CRM1 in pancreas cancer. Clin Invest Med 32:E315, 2009

9. Noske A, Weichert W, Niesporek $S$, et al: Expression of the nuclear export protein chromosomal region maintenance/exportin 1/Xpo1 is a prognostic factor in human ovarian cancer. Cancer 112 1733-1743, 2008

10. Shen $A$, Wang $Y$, Zhao $Y$, et al: Expression of CRM1 in human gliomas and its significance in p27 expression and clinical prognosis. Neurosurgery 65 : 153-159, 2009; discussion 159-160

11. van der Watt PJ, Maske CP, Hendricks DT, et al: The Karyopherin proteins, Crm1 and Karyopherin beta1, are overexpressed in cervical cancer and are critical for cancer cell survival and proliferation. Int J Cancer 124:1829-1840, 2009

12. Yao $Y$, Dong $Y$, Lin $F$, et al: The expression of CRM1 is associated with prognosis in human osteosarcoma. Oncol Rep 21:229-235, 2009

13. Lapalombella $R$, Sun $Q$, Williams $K$, et al: Selective inhibitors of nuclear export show that CRM1/XPO1 is a target in chronic lymphocytic leukemia. Blood 120:4621-4634, 2012

14. Yoshimura M, Ishizawa J, Ruvolo V, et al: Induction of p53-mediated transcription and apoptosis by exportin-1 (XPO1) inhibition in mantle cell lymphoma. Cancer Sci 105:795-801, 2014
15. Nakayama R, Zhang YX, Czaplinski JT, et al: Preclinical activity of selinexor, an inhibitor of XPO1, in sarcoma. Oncotarget 7:16581-16592, 2016

16. Nair JS, Tap W, Vasudeva SD, et al: KPT-330, a selective small molecule inhibitor of nuclear export, is active in bone and soft tissue sarcoma. Presented at the 104th Annual Meeting of the American Association for Cancer Research, Washington, DC, April 6-10, 2013

17. Abdul Razak AR, Mau-Soerensen M, Gabrail NY, et al: First-in-class, first-in-human phase I study of selinexor, a selective inhibitor of nuclear export, in patients with advanced solid tumors. J Clin Oncol [epub ahead of print on February 29, 2016]

18. Eisenhauer EA, Therasse P, Bogaerts J, et al: New response evaluation criteria in solid tumours: Revised RECIST guideline (version 1.1). Eur J Cancer 45:228-247, 2009

19. US Department of Health and Human Services, Food and Drug Administration, Center for Drug Evaluation and Research: Guidance for Industry: Food-Effect Bioavailability and Fed Bioequivalence Studies. http:// www.fda.gov/downloads/Regulatorylnformation/ Guidances/UCM126833.pdf

20. Von Hoff DD, Stephenson JJ Jr, Rosen P, et al: Pilot study using molecular profiling of patients' tumors to find potential targets and select treatments for their refractory cancers. J Clin Oncol 28:4877-4883, 2010

21. Buyse $M$, Quinaux $E$, Hendlisz $A$, et al: Progression-free survival ratio as end point for phase II trials in advanced solid tumors. J Clin Oncol 29: e451-e452, 2011; author reply e453

22. Cousin S, Blay JY, Bertucci F, et al: Correlation between overall survival and growth modulation index in pre-treated sarcoma patients: A study from the French Sarcoma Group. Ann Oncol 24:2681-2685, 2013

23. Penel N, Demetri GD, Blay JY, et al: Growth modulation index as metric of clinical benefit assessment among advanced soft tissue sarcoma patients receiving trabectedin as a salvage therapy. Ann Oncol 24:537-542, 2013

24. Vogelstein B, Kinzler KW: The path to cancer: Three strikes and you're out. N Engl J Med 373: 1895-1898, 2015

25. Vogelstein B, Papadopoulos $N$, Velculescu VE, et al: Cancer genome landscapes. Science 339: 1546-1558, 2013

26. Morris LG, Chan TA: Therapeutic targeting of tumor suppressor genes. Cancer 121:1357-1368, 2015

27. Conforti F, Wang Y, Rodriguez JA, et al: Molecular pathways: Anticancer activity by inhibition of nucleocytoplasmic shuttling. Clin Cancer Res 21: 4508-4513, 2015
28. Fu SC, Huang HC, Horton $P$, et al: ValidNESs: A database of validated leucine-rich nuclear export signals. Nucleic Acids Res 41:D338-D343, 2013

29. Machlus K, Wu S, Carlson R, et al: Selinexorinduced thrombocytopenia results from the inhibition of megakaryocyte progenitor cells in the early stage of megakaryopoiesis. Blood 124, 2014 (abstr 1458)

30. Italiano A, Toulmonde M, Cioffi A, et al: Advanced well-differentiated/dedifferentiated liposarcomas: role of chemotherapy and survival. Ann Oncol 23:1601-1607, 2012

31. Schöffski P, Chawla S, Maki RG, et al: Eribulin versus dacarbazine in previously treated patients with advanced liposarcoma or leiomyosarcoma: A randomised, open-label, multicentre, phase 3 trial. Lancet 387:1629-1637, 2016

32. Demetri GD, von Mehren M, Jones RL, et al: Efficacy and safety of trabectedin or dacarbazine for metastatic liposarcoma or leiomyosarcoma after failure of conventional chemotherapy: Results of a phase III randomized multicenter clinical trial. J Clin Oncol 34: 786-793, 2016

33. Moll UM, Petrenko O: The MDM2-p53 interaction. Mol Cancer Res 1:1001-1008, 2003

34. Nie L, Sasaki M, Maki CG: Regulation of p53 nuclear export through sequential changes in conformation and ubiquitination. J Biol Chem 282: 14616-14625, 2007

35. Agaram NP, Zhang L, LeLoarer $F$, et al: Targeted exome sequencing profiles genetic alterations in leiomyosarcoma. Genes Chromosomes Cancer 55:124-130, 2016

36. Scripture CD, Figg WD: Drug interactions in cancer therapy. Nat Rev Cancer 6:546-558, 2006

37. Ryan CJ, Smith MR, Fong $L$, et al: Phase I clinical trial of the CYP17 inhibitor abiraterone acetate demonstrating clinical activity in patients with castration-resistant prostate cancer who received prior ketoconazole therapy. J Clin Oncol 28:1481-1488, 2010

38. Ratain MJ, Cohen EE: The value meal: How to save $\$ 1,700$ per month or more on lapatinib. J Clin Oncol 25:3397-3398, 2007

39. Baer M: Nilotinib risk evaluation and mitigation strategy. Clin Adv Hematol Oncol 9:539-540, 2011

40. Ratain MJ: Flushing oral oncology drugs down the toilet. J Clin Oncol 29:3958-3959, 2011

41. Kang SP, Ratain MJ: Inconsistent labeling of food effect for oral agents across therapeutic areas: Differences between oncology and non-oncology products. Clin Cancer Res 16:4446-4451, 2010

42. Jain RK, Brar SS, Lesko LJ: Food and oral antineoplastics: More than meets the eye. Clin Cancer Res 16:4305-4307, 2010

Mrinal M. Gounder, William D. Tap, Mark A. Dickson, Mary Louise Keohan, Sandra P. D’Angelo, Mercedes Condy, Lanier Tanner, Joseph P. Erinjeri, and Francis H. Jasmine, Memorial Sloan Kettering Cancer Center and Weill Cornell Medical College; Gary K. Schwartz, Columbia University Medical Center, New York, NY; Alona Zer, Samer Salah, Abha A. Gupta, Herbert H. Loong, Stephanie Baker, Kjirsten Nyquist-Schultz, and Albiruni Ryan Abdul Razak, Princess Margaret Cancer Center, Toronto, Ontario, Canada; and Sharon Friedlander, Robert Carlson, Thaddeus J. Unger, Jean-Richard Saint-Martin, Tami Rashal, Joel Ellis, Michael Kauffman, and Sharon Shacham, Karyopharm Therapeutics, Newton, MA. 


\section{AUTHORS' DISCLOSURES OF POTENTIAL CONFLICTS OF INTEREST}

Phase IB Study of Selinexor, a First-in-Class Inhibitor of Nuclear Export, in Patients With Advanced Refractory Bone or Soft Tissue Sarcoma

The following represents disclosure information provided by authors of this manuscript. All relationships are considered compensated. Relationships are self-held unless noted. I = Immediate Family Member, Inst = My Institution. Relationships may not relate to the subject matter of this manuscript. For more information about ASCO's conflict of interest policy, please refer to www.asco.org/rwc or jco.ascopubs.org/site/ifc.

Mrinal M. Gounder

Honoraria: Amgen, Daiichi Sankyo, Karyopharm Therapeutics

Consulting or Advisory Role: Amgen, Daiichi Sankyo, Karyopharm

Therapeutics

Speakers' Bureau: Amgen

Travel, Accommodations, Expenses: Amgen, Daiichi Sankyo,

Karyopharm Therapeutics

\section{Alona Zer}

No relationship to disclose

William D. Tap

Consulting or Advisory Role: Advaxis, ARIAD Pharmaceuticals, EMD Serono, Plexxikon, Janssen Pharmaceuticals, Eli Lilly, Daiichi Sankyo, Eisai Other Relationship: Morphotek

\section{Samer Salah}

No relationship to disclose

Mark A. Dickson

No relationship to disclose

Abha A. Gupta

No relationship to disclose

Mary Louise Keohan

No relationship to disclose

Herbert H. Loong

Consulting or Advisory Role: GlaxoSmithKline, Genentech

Speakers' Bureau: AbbVie

Travel, Accommodations, Expenses: Bayer HealthCare Pharmaceuticals, Roche, Pfizer, Novartis

Sandra P. D'Angelo

No relationship to disclose

Stephanie Baker

Travel, Accommodations, Expenses: Eli Lilly

Mercedes Condy

No relationship to disclose

Kjirsten Nyquist-Schultz

No relationship to disclose

Lanier Tanner

No relationship to disclose

Joseph P. Erinjeri

No relationship to disclose

Francis H. Jasmine

No relationship to disclose

Sharon Friedlander

Employment: Karyopharm Therapeutics

Stock or Other Ownership: Karyopharm Therapeutics

Robert Carlson

Employment: Kiniksa Pharmaceuticals, Karyopharm Therapeutics

Stock or Other Ownership: Karyopharm Therapeutics

\section{Thaddeus J. Unger}

Employment: Karyopharm Therapeutics

Stock or Other Ownership: Karyopharm Therapeutics

Jean-Richard Saint-Martin

Employment: Karyopharm Therapeutics

Stock or Other Ownership: Karyopharm Therapeutics

Tami Rashal

Employment: Karyopharm Therapeutics, Karyopharm Therapeutics (I) Stock or Other Ownership: Karyopharm Therapeutics, Karyopharm Therapeutics (I)

Patents, Royalties, Other Intellectual Property: Karyopharm

Therapeutics patent (I)

Other Relationship: Karyopharm Therapeutics (I)

Joel Ellis

Employment: Karyopharm Therapeutics

Stock or Other Ownership: Karyopharm Therapeutics

Michael Kauffman

Employment: Karyopharm Therapeutics, Karyopharm Therapeutics (I)

Leadership: Karyopharm Therapeutics, Karyopharm Therapeutics (I), Verastem, Metamark Genetics

Stock or Other Ownership: Karyopharm Therapeutics, Karyopharm

Therapeutics (I)

Patents, Royalties, Other Intellectual Property: Karyopharm

Therapeutics, Karyopharm Therapeutics (I)

Sharon Shacham

Employment: Karyopharm Therapeutics, Karyopharm Therapeutics (I)

Leadership: Verastem (I), Metamark Genetics (I)

Stock or Other Ownership: Karyopharm Therapeutics, Karyopharm Therapeutics (I)

Consulting or Advisory Role: Verastem (I), Metamark Genetics (I)

Patents, Royalties, Other Intellectual Property: Karyopharm

Therapeutics patent (Inst)

Other Relationship: Karyopharm Therapeutics (I)

Gary K. Schwartz

Honoraria: Novartis, AstraZeneca, Boehringer Ingelheim, Daiichi Sankyo Consulting or Advisory Role: Novartis, AstraZeneca, Boehringer Ingelheim, Daiichi Sankyo

Patents, Royalties, Other Intellectual Property: Patent pending regarding development of PNAs for targeted cancer therapy (new technology)

Travel, Accommodations, Expenses: Novartis, AstraZeneca, Boehringer Ingelheim, Daiichi Sankyo

Albiruni Ryan Abdul Razak

Research Funding: Merck, Karyopharm Therapeutics, Novartis, EntreMed, Pfizer, MedImmune, Bristol-Myers Squibb, Genentech, Boston Biomedical, Boehringer Ingelheim 


\section{Acknowledgment}

We thank Hua Chang and Eran Shacham from Karyopharm Therapeutics for their contributions to the pharmacodynamic and drug safety analyses.

\section{Appendix}

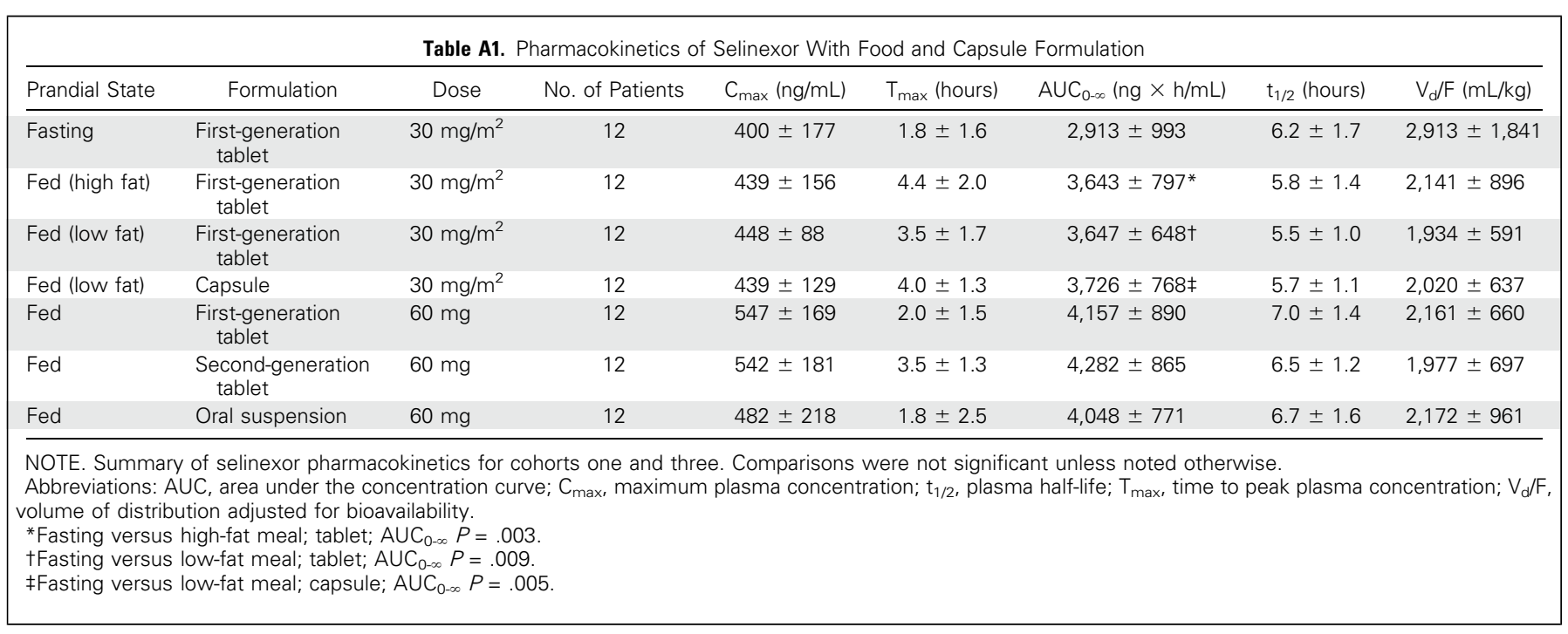

\begin{tabular}{|c|c|c|c|c|c|c|c|}
\hline Sarcoma Subtype & Biopsy Site & $\begin{array}{c}\text { Biopsy } \\
\text { Composition }\end{array}$ & $\begin{array}{l}\text { Biopsy } \\
\text { Collection } \\
\text { Time }\end{array}$ & $\begin{array}{l}\text { Ratio (cell } \\
\text { to stroma) }\end{array}$ & $\begin{array}{c}\text { Necrosis } \\
(\%)\end{array}$ & $\begin{array}{l}\text { Ki67-Positive } \\
\text { Tumor Cells (\%) }\end{array}$ & $\begin{array}{l}\text { Overall Treatment } \\
\text { Response }\end{array}$ \\
\hline DD liposarcoma & $\begin{array}{l}\text { Left abdominal } \\
\quad \text { wall }\end{array}$ & $\begin{array}{l}85 \% \text { nonlipogenic } \\
\text { component; } \\
10 \% \text { lipogenic } \\
\text { component }\end{array}$ & $\begin{array}{l}\text { Pretreatment } \\
\text { During } \\
\text { treatment }\end{array}$ & $\begin{array}{l}90: 10 \\
10: 90\end{array}$ & $\begin{array}{r}5 \\
45\end{array}$ & $\begin{array}{r}35 \\
5\end{array}$ & $\begin{array}{l}\text { Marked reduction in cellularity, } \\
\text { increased necrosis, and strong } \\
\text { stromal response }\end{array}$ \\
\hline DD liposarcoma & $\begin{array}{l}\text { Lower left } \\
\text { quadrant } \\
\text { pelvic mass }\end{array}$ & $\begin{array}{l}100 \% \text { nonlipogenic } \\
\text { component; } 0 \% \\
\text { lipogenic } \\
\text { component }\end{array}$ & $\begin{array}{l}\text { Pretreatment } \\
\text { During } \\
\text { treatment }\end{array}$ & $\begin{array}{l}85: 15 \\
75: 25\end{array}$ & $\begin{array}{l}0 \\
5\end{array}$ & $\begin{array}{l}55 \\
45\end{array}$ & $\begin{array}{l}\text { Moderate reduction in cellularity, } \\
\text { minimal necrosis, and } \\
\text { increased stromal response }\end{array}$ \\
\hline DD liposarcoma & $\begin{array}{l}\text { Left mesenteric } \\
\text { mass }\end{array}$ & $\begin{array}{l}100 \% \text { nonlipogenic } \\
\text { component; } 0 \% \\
\text { lipogenic } \\
\text { component }\end{array}$ & $\begin{array}{l}\text { Pretreatment } \\
\text { During } \\
\text { treatment }\end{array}$ & $\begin{array}{l}95: 5 \\
80: 20\end{array}$ & $\begin{array}{r}35 \\
0\end{array}$ & $\begin{array}{l}70 \\
60\end{array}$ & $\begin{array}{l}\text { Moderate reduction in cellularity, } \\
\text { no necrosis, and increased } \\
\text { stromal response }\end{array}$ \\
\hline DD liposarcoma & Pelvic mass & $\begin{array}{l}100 \% \text { nonlipogenic } \\
\text { component; 0\% } \\
\text { lipogenic } \\
\text { component }\end{array}$ & $\begin{array}{l}\text { Pretreatment } \\
\text { During } \\
\text { treatment }\end{array}$ & $\begin{array}{l}80: 20 \\
60: 40\end{array}$ & $\begin{array}{l}0 \\
0\end{array}$ & $\begin{array}{l}30 \\
25\end{array}$ & $\begin{array}{l}\text { Moderate reduction in cellularity, } \\
\text { no necrosis, and increased } \\
\text { stromal response }\end{array}$ \\
\hline DD liposarcoma & Pelvic mass & $\begin{array}{l}5 \% \text { nonlipogenic } \\
\text { component; } \\
95 \% \text { lipogenic } \\
\text { component }\end{array}$ & $\begin{array}{l}\text { Pretreatment } \\
\text { During } \\
\text { treatment }\end{array}$ & ND & $\begin{array}{l}0 \\
0\end{array}$ & $\begin{array}{l}65 \\
65\end{array}$ & No response \\
\hline
\end{tabular}




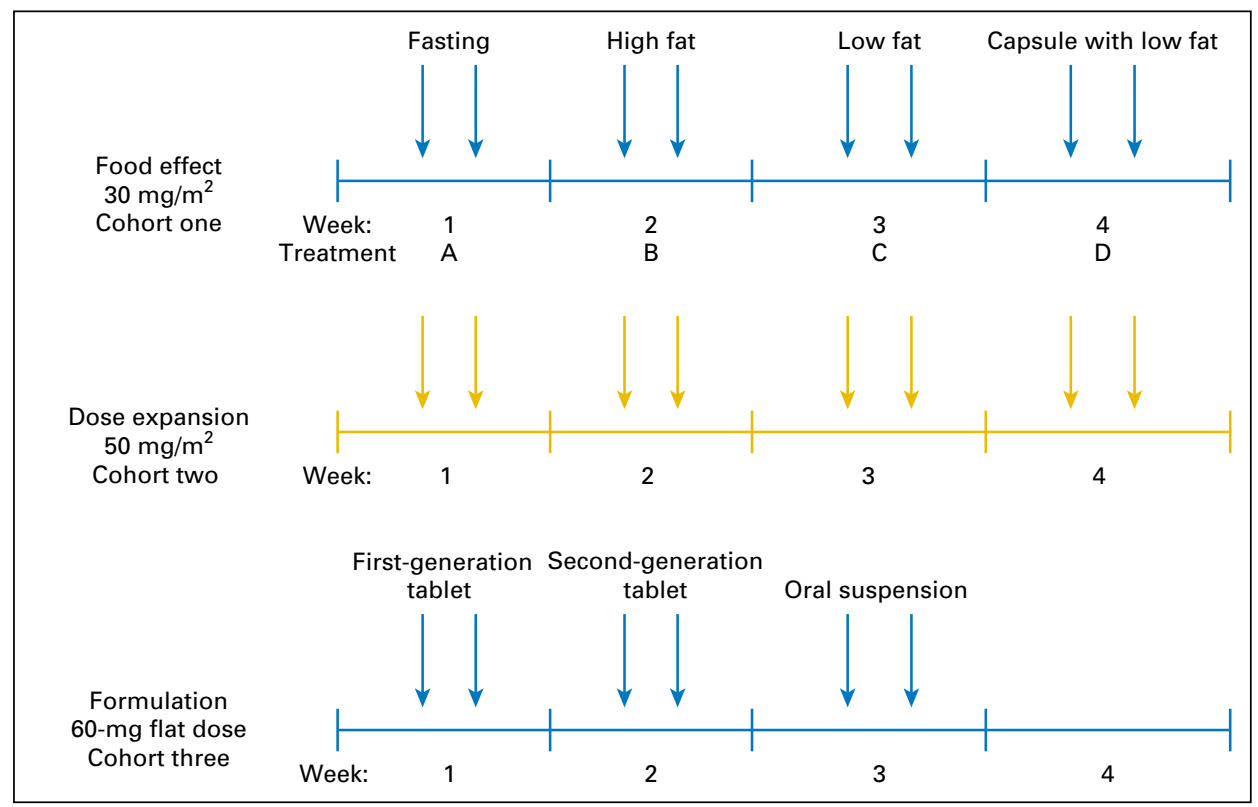

Fig A1. Schematic of trial design. Arrows indicate selinexor treatment (Monday and Wednesday).

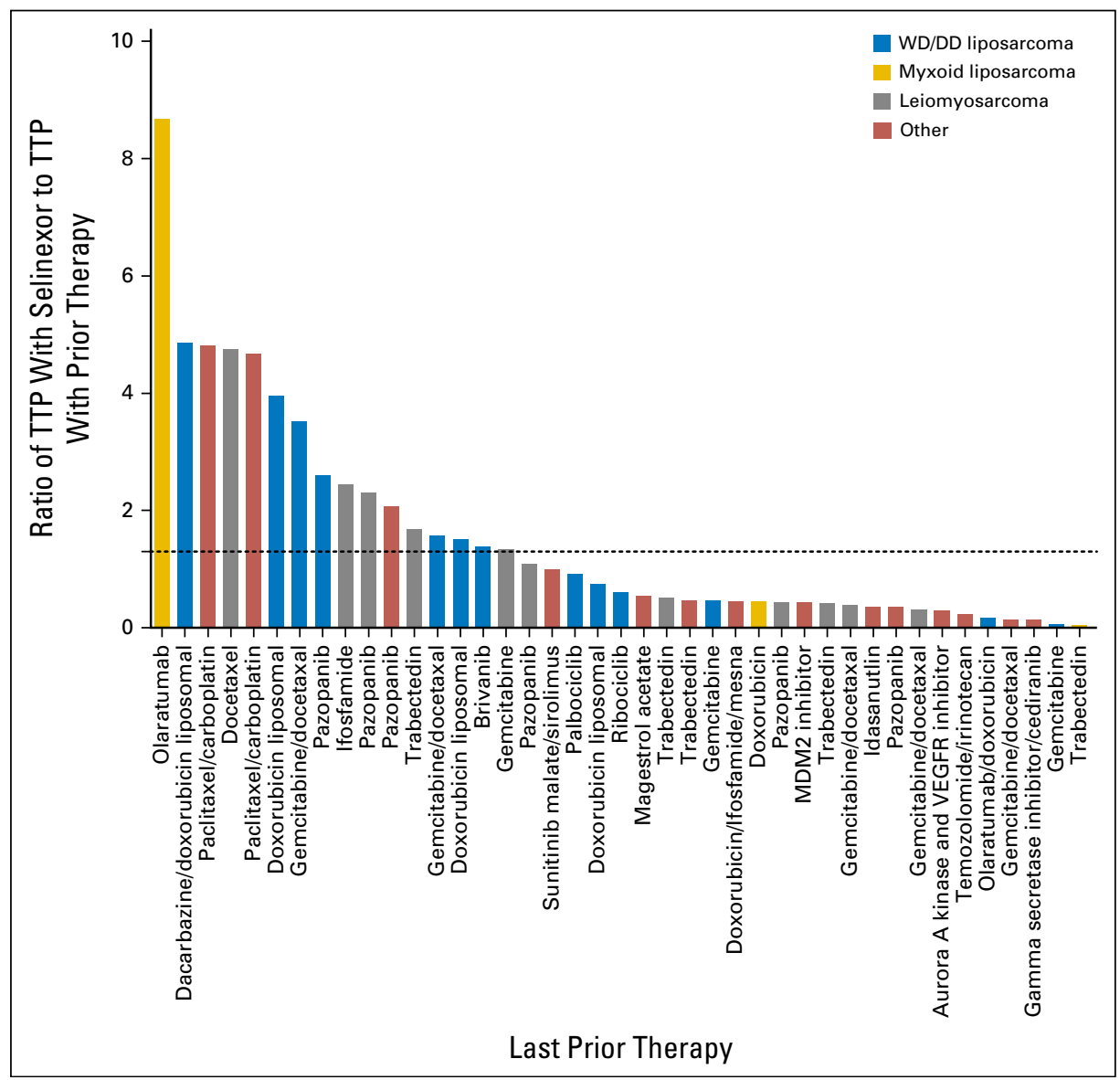

Fig A2. Time to disease progression (TTP) with selinexor versus TTP with last prior therapy for 41 evaluable patients. Dotted line represents greater than 1.3-fold increase

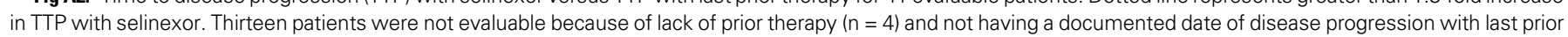
therapy $(n=9)$. DD, dedifferentiated; VEGFR, vascular endothelial growth factor receptor; WD, well differentiated. 


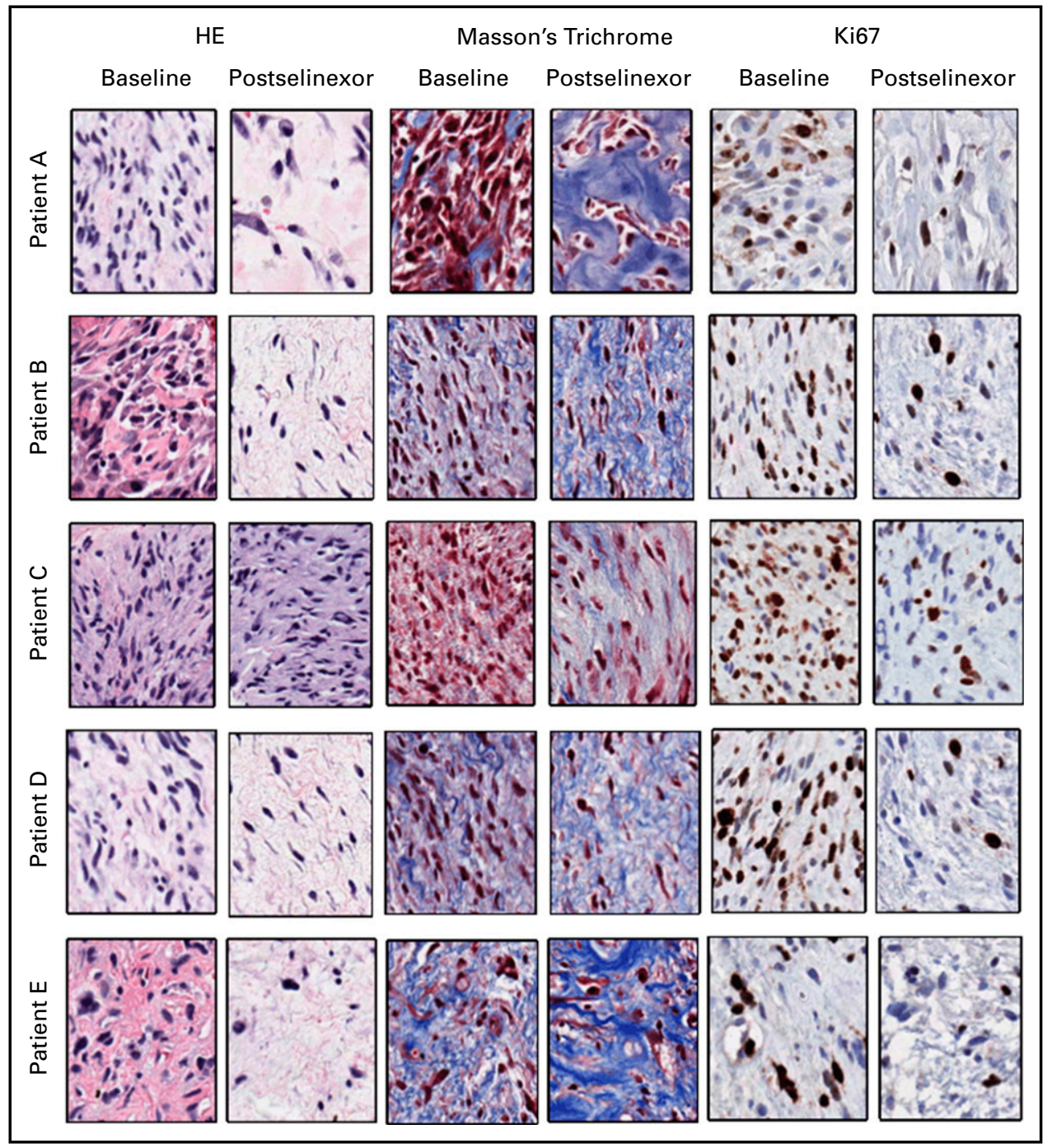

Fig A3. Histopathologic evaluation of liposarcoma biopsies. Tumor biopsies from five patients with liposarcoma were collected at baseline or during week 3 or 4 of selinexor treatment and were evaluated by a blinded histopathologist for changes in cell-to-stroma ratio, percent necrosis, and percent Ki67-positive tumor cells. HE, hematoxylin and eosin. 